${ }^{1} \mathrm{PhD}$ in Orthodontics, Juiz de Fora Federal University

${ }^{2}$ Master Student, Juiz de Fora Federal University

${ }^{3}$ Undergraduate Student, Juiz de Fora Federal University

${ }^{4}$ Undergraduate Student, Juiz de Fora Federal University
Corresponding author:

Paula Liparini Caetano Ivon José Cury 2, Juiz de Fora MG, 36037-467, Brazil

5532 3231-1444; 5532 98853-3166 paulaliparini@gmail.com and xpaulinha1@hotmail.com

Received: April 7, 2017

Accepted: August 09, 2017

\section{Transverse dimension of the alveolar bone in different masticatory patterns}

\author{
Marcio José da Silva Campos ${ }^{1}$, Paula Liparini \\ Caetano ${ }^{2}$, Fernanda Farage da Costa Felipe ${ }^{3}$, Gabriella \\ Moreira de Carvalho ${ }^{4}$, Marcelo Reis Fraga ${ }^{1}$, Robert \\ Willer Farinazzo Vitral ${ }^{1}$
}

Aim: The aim of this study was to evaluate, through cone beam computed tomography ( $\mathrm{CBCT}$ ), the transverse dimension of the alveolar bone in the posterior region of the maxilla and mandible in subjects with different patterns of mastication, comparing both sides of the arches according to the performance of the masticatory function. Methods: 39 subjects not orthodontically treated, with normal occlusion or symmetrical malocclusion, and normal periodontal condition were selected. Twenty-one subjects (54\%) were identified as having preferential unilateral mastication, 11 subjects $(28 \%)$ had bilateral mastication and 7 (18\%) had exclusive unilateral mastication. All participants were submitted to CBCT and the buccolingual dimension of the posterior regions was evaluated at a height of 2, 4, 6, 8, and 10mm from the alveolar crest. Results and Conclusion: Subjects with bilateral mastication showed statistically significant difference between the right and left sides at the heights of $6(p=0.030)$ and $8 \mathrm{~mm}$ $(p=0.023)$ between the first and second maxillary premolars. There was no difference in the transverse dimension of the alveolar bone in the posterior regions of maxilla and mandible between preferred and non-preferred sides in subjects with preferred unilateral mastication and between right and left sides in subjects with bilateral mastication.

Keywords: Alveolar process. Bone. Cone-beam computed tomography. Mastication. 


\section{Introduction}

Mastication is one of the most important functions of the stomatognathic system because it is related to nutrition, maturation of the orofacial musculature, occlusal stability, temporomandibular joints and growth and development of the craniofacial complex, as well as a necessary factor for a perfect homeostasis of the human being ${ }^{1}$.

When considering the health of the stomatognathic system, a desirable pattern of mastication is required, which is characterized by unilateral cycles with periodic alternation of food between the right and left sides, distributing the force of mastication on the teeth and structures of support on both sides of the dental arches ${ }^{2,3}$, what results in greater masticatory efficiency ${ }^{4-6}$. However, this bilateral pattern of distribution of food is not present in most of the population, where a preferred chewing side is more common ${ }^{7,8}$. The choice for a preferred chewing side is a voluntary decision that becomes involuntary with function performance ${ }^{9}$ and may be associated with the control of the central nervous system ${ }^{10}$ or related to peripheral factors ${ }^{9}$.

Since teeth are supported by the alveolar process, this bone structure is directly exposed to mechanical loads created by the functional performance of the maxilla and mandible ${ }^{11}$. Bone tissue is in a constant process of functional adaptation through modeling and remodeling mechanisms, which are significantly influenced by mechanical stimuli12. Thus, the masticatory function provides mechanical stimuli capable of influencing the formation, maintenance and remodeling of the craniofacial skeleton, exerting an important function in the regulation of the mass and bone architecture of this region ${ }^{13}$.

Changes in intensity and/or frequency of functional load may be accompanied by changes in the alveolar bone ${ }^{12,14-16}$. In studies with rats, implementation of soft diet ${ }^{14,17}$ or placement of anterior ${ }^{18}$ and posterior ${ }^{12}$ occlusal build-ups produced changes in the occlusal force applied to the teeth and distributed in the alveolar process, resulting in significant qualitative and quantitative alterations in the alveolar bone tissue. However, the hypothesis that the dimension of the alveolar bone can be influenced by functional loading was not tested.

The purpose of this study was to evaluate, through cone beam computed tomography (CBCT), the transverse dimension of the alveolar bone in the posterior regions of the maxilla and mandible in subjects with different patterns of mastication, comparing both sides of the arches according to the performance of the masticatory function.

The hypothesis of this study is that the transverse dimension of the alveolar bone in the posterior regions of the maxilla and mandible is greater in the preferred side than in the non-preferred side in subjects with preferred and exclusive unilateral mastication. Such difference does not exist between the right and left sides in subjects with bilateral mastication.

\section{Material and methods}

The sample consisted of 39 subjects, not orthodontically treated, between 19.2 and 44.6 years (mean: 24,3 years) with complete permanent dentition (except 
third molars), normal occlusion or symmetrical malocclusion, and normal periodontal condition, as assessed by visual evaluation. This study was approved by the Research Ethics Committee of the of the Juiz de Fora Federal University, and all participants signed an informed consent form.

\section{Determination of the preferred chewing side}

The first phase of this research consisted in determining the masticatory pattern of the subject by means of a visual method ${ }^{19,20}$ where the participant was seated in an upright position in a chair with their backs towards a white background, their hands resting on their legs, and looking fixedly at the digital video camera (Sony MHS-PM5), which was placed on a fixed tripod one meter away from the chair back at the height of their mandible. Each subject was filmed chewing on a piece of French bread in their habitual manner for approximately 90 seconds.

The videos were analyzed by 3 speech therapists who counted the masticatory cycles in each hemi-arch and determined, unanimously, the masticatory pattern of each participant, classifying it as bilateral (occurrence of up to $60 \%$ of the cycles in one side), preferred unilateral (occurrence from $61 \%$ to $77 \%$ of the cycles in one side) or exclusive unilateral (occurrence from $78 \%$ to $94 \%$ of the cycles in one side) ${ }^{21}$.

From the total of 39 subjects, 21 (54\%) were identified as having preferred unilateral chewing (13 right and 8 left), 11 (28\%) bilateral chewing, and 7 (18\%) exclusive unilateral chewing (2 right and 5 left).

\section{Evaluation of the transverse dimension of the alveolar bone}

All participants were submitted to cone-beam computed tomography (CBCT) (i-CAT-Imaging Sciences International, Hatfield, PA - USA), operated at $120 \mathrm{kV}$ and 3-8 mmA, voxel of $0.25 \mathrm{~mm}$, rotation time of 26.9s, and field of view with a diameter of $160 \mathrm{~mm}$ and height of $100 \mathrm{~mm}$.

For image acquisition, each subject was seated with the chin on the chin rest, with the Frankfort plane parallel to the floor, the midsagittal plane perpendicular to the floor and with the participant in maximum intercuspation position. The field of view was positioned in a way that the occlusal plane occupied its vertical center and the anterior nasal spine was at $35 \mathrm{~mm}$ from its anterior border.

Images were analyzed with the i-CAT Vision (Imaging Sciences International Inc., Hatfield, USA) software, on MPR visualization mode (multiplanar reconstruction), with $0.5 \mathrm{~mm}$-thick slices.

Initially, for the definition of the images of the posterior interdental regions, the line corresponding to the coronal slice was centrically positioned in the posterior interdental areas (vertical line - figure 1b) and perpendicular to the alveolar process buccolingually (horizontal line - figure 1a). The line corresponding to the sagittal slice was positioned in the long axis of the alveolar process (vertical line - figure 1c). The posterior interdental regions between maxillary and mandibular canine and first premolar, first and second premolar, second premolar and first molar and first and second molars of both sides were evaluated (figure 1b). 

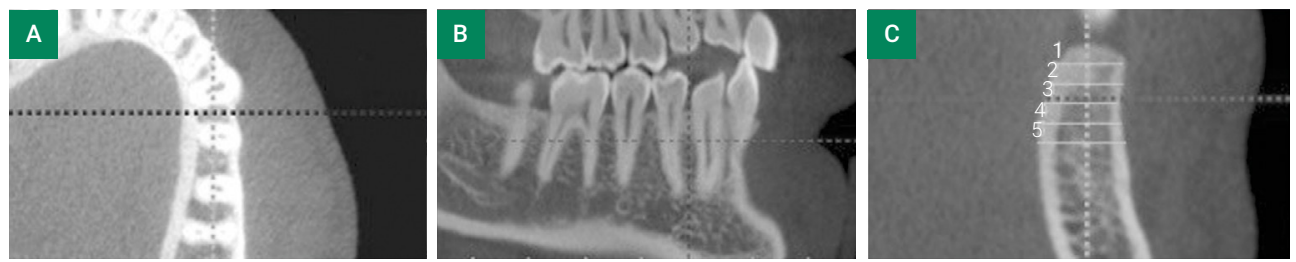

Figure 1. Definition of the interdental image and determination of the transverse dimension of the alveolar process on axial (a), sagittal (b), and coronal (c) cuts.

Buccolingual dimensions of the posterior interdental regions were determined at the heights of 2, 4, 6, 8 and $10 \mathrm{~mm}$ from the alveolar bone crest (figure 1c), including the bone height where the roots of the posterior teeth were located. Measurements were performed by two examiners in a blind manner, where examiner 1 measured teeth quadrants 1 and 3 and examiner 2 measured teeth quadrants 2 and 4 .

\section{Statistics}

Intra- and inter-examiner agreement was determined by intraclass correlation coefficient, which was calculated on the basis of the values of the buccolingual dimensions of 3 (240 measurements) randomly chosen participants and measured twice by the examiners with a 20-day interval.

The distribution pattern of the values of the buccolingual dimensions was evaluated by the Shapiro-Wilk test, where the variable showed normal distribution.

The comparison between the preferred chewing side and the opposite side for the participants with preferred and exclusive unilateral mastication and between the right and left sides for the subjects with bilateral mastication was performed with the Student t test for paired samples. Statistical analysis used a level of significance of $\mathrm{a}=0.05$ and the data were processed with the SPSS Statistics 17.0.0 software (SPSS, Chicago, IL, USA).

\section{Results}

Intra- and inter-examiner agreement for the buccolingual dimensions were 0.959 $(p<0.001)$ and $0.979(p<0.001)$ respectively, demonstrating excellent agreement.

The mean values for the maxillary and mandibular buccolingual dimensions of the alveolar process in subjects with preferred unilateral, bilateral and exclusive unilateral masticatory patterns, as well as the comparison between comparable sides (the preferred and non-preferred sides, right and left sides, and mastication and balancing sides) are shown in tables 1 to 3.

Subjects with preferred unilateral and exclusive unilateral mastication did not show statistically significant difference between the preferred and non-preferred sides and the chewing and balancing sides, respectively, for both the maxilla and mandible.

Subjects with bilateral mastication showed statistically significant difference between the right and left sides at the heights of $6 \mathrm{~mm}(p=0.030)$ and $8 \mathrm{~mm}(p=0.023)$ between the first and second maxillary premolars. 
Table 1. Mean values of the buccolingual dimensions of the alveolar bone in subjects with preferred unilateral mastication.

\begin{tabular}{|c|c|c|c|c|c|c|c|c|c|c|c|}
\hline \multirow{3}{*}{$\begin{array}{l}\text { Interdental } \\
\text { region }\end{array}$} & \multirow{3}{*}{ Height } & \multicolumn{5}{|c|}{ Maxilla } & \multicolumn{5}{|c|}{ Mandible } \\
\hline & & \multicolumn{2}{|c|}{$\begin{array}{l}\text { Preferred } \\
\text { side }\end{array}$} & \multicolumn{2}{|c|}{$\begin{array}{l}\text { Non-preferred } \\
\text { side }\end{array}$} & \multirow[t]{2}{*}{$\mathrm{P}$ Value } & \multicolumn{2}{|c|}{$\begin{array}{l}\text { Preferred } \\
\text { side }\end{array}$} & \multicolumn{2}{|c|}{$\begin{array}{c}\text { Non-preferred } \\
\text { side }\end{array}$} & \multirow[t]{2}{*}{ P Value } \\
\hline & & Mean & SD & Mean & SD & & Mean & SD & Mean & SD & \\
\hline \multirow{5}{*}{$\begin{array}{c}\text { Canine } \\
X \\
1^{\text {rst }} \text { Premolar }\end{array}$} & $2 \mathrm{~mm}$ & 7.89 & 0.75 & 7.92 & 1.00 & 0.892 & 7.47 & 1.18 & 7.40 & 1.07 & 0.758 \\
\hline & $4 \mathrm{~mm}$ & 8.67 & 0.94 & 8.83 & 0.98 & 0.332 & 8.58 & 1.39 & 8.55 & 1.55 & 0.929 \\
\hline & $6 \mathrm{~mm}$ & 9.15 & 1.22 & 9.11 & 1.33 & 0.841 & 8.90 & 1.37 & 8.76 & 1.41 & 0.432 \\
\hline & $8 \mathrm{~mm}$ & 9.45 & 1.62 & 9.28 & 1.52 & 0.509 & 9.14 & 1.47 & 9.05 & 1.53 & 0.685 \\
\hline & $10 \mathrm{~mm}$ & 9.88 & 1.96 & 9.77 & 2.03 & 0.765 & 9.47 & 1.66 & 9.53 & 1.80 & 0.843 \\
\hline \multirow{5}{*}{$\begin{array}{c}1^{\text {rst }} \text { Premolar } \\
X \\
2^{\text {nd }} \text { Premolar }\end{array}$} & $2 \mathrm{~mm}$ & 9.38 & 0.96 & 9.19 & 0.86 & 0.239 & 8.16 & 1.83 & 8.02 & 1.27 & 0.681 \\
\hline & $4 \mathrm{~mm}$ & 9.83 & 1.09 & 9.89 & 1.17 & 0.680 & 9.35 & 1.79 & 8.98 & 1.34 & 0.201 \\
\hline & $6 \mathrm{~mm}$ & 9.95 & 1.34 & 10.02 & 1.20 & 0.722 & 9.67 & 1.70 & 9.53 & 1.51 & 0.528 \\
\hline & $8 \mathrm{~mm}$ & 10.05 & 1.38 & 10.02 & 1.40 & 0.852 & 9.94 & 1.59 & 9.76 & 1.59 & 0.380 \\
\hline & $10 \mathrm{~mm}$ & 10.31 & 1.69 & 10.20 & 1.78 & 0.535 & 10.08 & 1.55 & 10.15 & 1.55 & 0.702 \\
\hline \multirow{5}{*}{$\begin{array}{c}2^{\text {nd }} \text { Premolar } \\
X \\
1^{\text {rst }} \text { Molar }\end{array}$} & $2 \mathrm{~mm}$ & 10.34 & 1.16 & 10.34 & 1.22 & 1.000 & 9.65 & 1.29 & 9.50 & 1.04 & 0.539 \\
\hline & $4 \mathrm{~mm}$ & 11.15 & 1.11 & 11.22 & 1.07 & 0.562 & 10.80 & 1.34 & 10.58 & 1.22 & 0.303 \\
\hline & $6 \mathrm{~mm}$ & 11.38 & 1.62 & 11.30 & 1.59 & 0.577 & 11.08 & 1.40 & 11.15 & 1.53 & 0.705 \\
\hline & $8 \mathrm{~mm}$ & 11.38 & 1.88 & 11.40 & 1.81 & 0.942 & 11.20 & 1.64 & 11.41 & 1.65 & 0.314 \\
\hline & $10 \mathrm{~mm}$ & 12.13 & 2.00 & 12.13 & 1.98 & 1.000 & 11.25 & 1.60 & 11.52 & 1.88 & 0.237 \\
\hline \multirow{5}{*}{$\begin{array}{c}1^{\text {rst }} \text { Molar } \\
X \\
2^{\text {nd }} \text { Molar }\end{array}$} & $2 \mathrm{~mm}$ & 13.01 & 1.09 & 13.11 & 0.90 & 0.597 & 11.19 & 1.19 & 11.04 & 1.33 & 0.219 \\
\hline & $4 \mathrm{~mm}$ & 13.67 & 1.02 & 13.92 & 0.81 & 0.165 & 12.40 & 1.43 & 12.34 & 1.38 & 0.717 \\
\hline & $6 \mathrm{~mm}$ & 14.33 & 1.14 & 14.36 & 1.14 & 0.900 & 13.32 & 1.65 & 13.21 & 1.58 & 0.623 \\
\hline & $8 \mathrm{~mm}$ & 14.18 & 0.85 & 14.45 & 1.13 & 0.355 & 13.43 & 1.62 & 13.33 & 1.46 & 0.565 \\
\hline & $10 \mathrm{~mm}$ & 15.80 & 2.01 & 16.45 & 2.98 & 0.552 & 13.22 & 1.81 & 13.34 & 1.58 & 0.521 \\
\hline
\end{tabular}

Table 2. Mean values of the buccolingual dimensions of the alveolar bone in subjects with bilateral mastication.

\begin{tabular}{|c|c|c|c|c|c|c|c|c|c|c|c|}
\hline \multirow{3}{*}{$\begin{array}{l}\text { Interdental } \\
\text { region }\end{array}$} & \multirow{3}{*}{ Height } & \multicolumn{5}{|c|}{ Maxilla } & \multicolumn{5}{|c|}{ Mandible } \\
\hline & & \multicolumn{2}{|c|}{ Right side } & \multicolumn{2}{|c|}{ Left side } & \multirow{2}{*}{$\mathrm{P}$ Value } & \multicolumn{2}{|c|}{ Right side } & \multicolumn{2}{|c|}{ Left side } & \multirow{2}{*}{$P$ Value } \\
\hline & & Mean & SD & Mean & SD & & Mean & SD & Mean & SD & \\
\hline \multirow{5}{*}{$\begin{array}{c}\text { Canine } \\
\text { X } \\
1^{\text {rst }} \text { Premolar }\end{array}$} & $2 \mathrm{~mm}$ & 8.00 & 1.31 & 8.02 & 1.11 & 0.952 & 7.09 & 0.91 & 7.40 & 1.31 & 0.358 \\
\hline & $4 \mathrm{~mm}$ & 8.93 & 1.28 & 9.15 & 1.10 & 0.447 & 8.50 & 1.30 & 8.75 & 1.27 & 0.345 \\
\hline & $6 \mathrm{~mm}$ & 9.22 & 1.30 & 9.27 & 1.19 & 0.896 & 8.97 & 1.55 & 8.93 & 1.41 & 0.829 \\
\hline & $8 \mathrm{~mm}$ & 9.36 & 1.50 & 9.31 & 1.33 & 0.899 & 9.04 & 1.77 & 9.13 & 1.65 & 0.777 \\
\hline & $10 \mathrm{~mm}$ & 9.56 & 1.46 & 9.34 & 1.03 & 0.615 & 9.18 & 1.83 & 9.43 & 2.00 & 0.448 \\
\hline \multirow{5}{*}{$\begin{array}{c}1^{\text {rst }} \text { Premolar } \\
X \\
2^{\text {nd }} \text { Premolar }\end{array}$} & $2 \mathrm{~mm}$ & 9.15 & 1.08 & 9.09 & 0.11 & 0.732 & 7.88 & 1.48 & 8.20 & 1.71 & 0.322 \\
\hline & $4 \mathrm{~mm}$ & 9.90 & 1.63 & 9.38 & 1.02 & 0.118 & 9.15 & 1.91 & 9.29 & 1.81 & 0.523 \\
\hline & $6 \mathrm{~mm}$ & 9.97 & 1.45 & 9.45 & 1.16 & $0.030 *$ & 9.72 & 1.74 & 9.61 & 1.45 & 0.598 \\
\hline & $8 \mathrm{~mm}$ & 9.79 & 1.53 & 9.27 & 1.32 & $0.023^{*}$ & 10.13 & 1.49 & 10.13 & 1.26 & 1.000 \\
\hline & $10 \mathrm{~mm}$ & 9.77 & 0.80 & 9.50 & 1.31 & 0.323 & 10.50 & 1.46 & 10.38 & 1.46 & 0.450 \\
\hline \multirow{5}{*}{$\begin{array}{c}2^{\text {nd }} \text { Premolar } \\
\text { X } \\
1^{\text {rst }} \text { Molar }\end{array}$} & $2 \mathrm{~mm}$ & 10.31 & 1.37 & 10.77 & 1.10 & 0.064 & 9.61 & 1.24 & 9.50 & 1.58 & 0.742 \\
\hline & $4 \mathrm{~mm}$ & 11.40 & 1.24 & 11.20 & 0.07 & 0.455 & 10.75 & 1.46 & 10.72 & 1.57 & 0.921 \\
\hline & $6 \mathrm{~mm}$ & 11.56 & 0.61 & 11.22 & 1.43 & 0.151 & 11.36 & 1.69 & 11.40 & 1.51 & 0.835 \\
\hline & $8 \mathrm{~mm}$ & 11.57 & 2.09 & 11.25 & 1.64 & 0.231 & 11.61 & 1.81 & 11.47 & 1.55 & 0.628 \\
\hline & $10 \mathrm{~mm}$ & 11.17 & 3.04 & 11.28 & 2.22 & 0.807 & 11.65 & 1.91 & 11.63 & 1.76 & 0.918 \\
\hline \multirow{5}{*}{$\begin{array}{l}1^{\text {rst }} \text { Molar } \\
X \\
2^{\text {nd }} \text { Molar }\end{array}$} & $2 \mathrm{~mm}$ & 12.88 & 1.01 & 13.13 & 1.37 & 0.490 & 11.18 & 1.30 & 11.15 & 1.28 & 0.884 \\
\hline & $4 \mathrm{~mm}$ & 14.22 & 1.00 & 14.34 & 1.16 & 0.713 & 12.34 & 1.46 & 12.18 & 1.40 & 0.396 \\
\hline & $6 \mathrm{~mm}$ & 14.38 & 0.71 & 14.11 & 1.23 & 0.263 & 13.25 & 1.72 & 13.09 & 1.60 & 0.494 \\
\hline & $8 \mathrm{~mm}$ & 14.33 & 1.19 & 14.02 & 1.29 & 0.179 & 13.77 & 1.88 & 13.54 & 1.97 & 0.331 \\
\hline & $10 \mathrm{~mm}$ & 13.50 & 1.62 & 13.81 & 1.14 & 0.504 & 13.77 & 2.03 & 13.43 & 2.28 & 0.180 \\
\hline
\end{tabular}

* - statistically significant difference according to Student t test for paired samples. 
Table 3. Mean values of the buccolingual dimensions of the alveolar bone in subjects with exclusive unilateral mastication.

\begin{tabular}{|c|c|c|c|c|c|c|c|c|c|c|c|}
\hline \multirow{3}{*}{$\begin{array}{l}\text { Interdental } \\
\text { region }\end{array}$} & \multirow{3}{*}{ Height } & \multicolumn{5}{|c|}{ Maxilla } & \multicolumn{5}{|c|}{ Mandible } \\
\hline & & \multicolumn{2}{|c|}{ Chewing side } & \multicolumn{2}{|c|}{$\begin{array}{l}\text { Balancing } \\
\text { side }\end{array}$} & \multirow{2}{*}{ P Value } & \multicolumn{2}{|c|}{ Chewing side } & \multicolumn{2}{|c|}{$\begin{array}{l}\text { Balancing } \\
\text { side }\end{array}$} & \multirow{2}{*}{ P Value } \\
\hline & & Mean & SD & Mean & SD & & Mean & SD & Mean & SD & \\
\hline \multirow{5}{*}{$\begin{array}{c}\text { Canine } \\
X \\
1^{\text {rst }} \text { Premolar }\end{array}$} & $2 \mathrm{~mm}$ & 7.67 & 0.64 & 7.92 & 0.97 & 0.533 & 7.67 & 1.54 & 7.92 & 1.51 & 0.356 \\
\hline & $4 \mathrm{~mm}$ & 8.39 & 0.92 & 8.46 & 1.36 & 0.875 & 9.17 & 2.03 & 9.07 & 2.12 & 0.573 \\
\hline & $6 \mathrm{~mm}$ & 8.57 & 1.37 & 8.85 & 1.67 & 0.493 & 9.67 & 2.17 & 9.64 & 2.14 & 0.818 \\
\hline & $8 \mathrm{~mm}$ & 8.25 & 1.58 & 8.85 & 2.16 & 0.222 & 9.35 & 2.78 & 9.92 & 2.50 & 0.388 \\
\hline & $10 \mathrm{~mm}$ & 8.57 & 1.61 & 9.17 & 3.06 & 0.422 & 10.17 & 2.88 & 10.07 & 2.79 & 0.695 \\
\hline \multirow{5}{*}{$\begin{array}{c}1^{\text {rst }} \text { Premolar } \\
X \\
2^{\text {nd }} \text { Premolar }\end{array}$} & $2 \mathrm{~mm}$ & 9.28 & 1.43 & 9.07 & 1.24 & 0.585 & 8.67 & 1.68 & 8.25 & 1.43 & 0.111 \\
\hline & $4 \mathrm{~mm}$ & 9.82 & 1.59 & 9.71 & 1.12 & 0.815 & 9.67 & 2.26 & 9.60 & 1.88 & 0.778 \\
\hline & $6 \mathrm{~mm}$ & 9.92 & 1.71 & 9.92 & 1.79 & 1.000 & 10.28 & 2.33 & 10.03 & 1.91 & 0.403 \\
\hline & $8 \mathrm{~mm}$ & 10.39 & 1.95 & 10.35 & 1.74 & 0.945 & 10.42 & 2.46 & 10.60 & 2.11 & 0.499 \\
\hline & $10 \mathrm{~mm}$ & 10.60 & 2.51 & 10.60 & 2.27 & 1.000 & 10.46 & 2.95 & 10.92 & 2.35 & 0.308 \\
\hline \multirow{5}{*}{$\begin{array}{c}2^{\text {nd }} \text { Premolar } \\
X \\
1^{\text {rst }} \text { Molar }\end{array}$} & $2 \mathrm{~mm}$ & 10.25 & 1.02 & 10.39 & 0.80 & 0.558 & 9.39 & 1.48 & 9.96 & 2.37 & 0.403 \\
\hline & $4 \mathrm{~mm}$ & 11.16 & 0.58 & 11.75 & 0.93 & 0.052 & 10.39 & 2.02 & 10.89 & 1.36 & 0.197 \\
\hline & $6 \mathrm{~mm}$ & 11.79 & 1.02 & 11.91 & 1.47 & 0.832 & 10.96 & 2.00 & 11.53 & 1.53 & 0.084 \\
\hline & $8 \mathrm{~mm}$ & 12.10 & 1.52 & 12.40 & 1.85 & 0.485 & 11.17 & 2.12 & 12.00 & 1.53 & 0.054 \\
\hline & $10 \mathrm{~mm}$ & 13.00 & 2.88 & 13.18 & 3.27 & 0.547 & 11.60 & 2.56 & 12.07 & 1.85 & 0.239 \\
\hline \multirow{5}{*}{$\begin{array}{c}1^{\text {rst }} \text { Molar } \\
X \\
2^{\text {nd }} \text { Molar }\end{array}$} & $2 \mathrm{~mm}$ & 12.25 & 0.76 & 12.82 & 1.37 & 0.306 & 10.96 & 1.26 & 11.00 & 1.02 & 0.864 \\
\hline & $4 \mathrm{~mm}$ & 13.85 & 1.00 & 13.75 & 1.10 & 0.448 & 12.28 & 1.04 & 12.28 & 1.30 & 1.000 \\
\hline & $6 \mathrm{~mm}$ & 14.25 & 0.88 & 14.54 & 1.27 & 0.384 & 13.60 & 1.12 & 13.10 & 1.26 & 0.221 \\
\hline & $8 \mathrm{~mm}$ & 14.50 & 0.90 & 15.12 & 1.49 & 0.098 & 14.14 & 1.42 & 14.03 & 1.29 & 0.796 \\
\hline & $10 \mathrm{~mm}$ & 15.37 & 1.45 & 16.12 & 2.21 & 0.223 & 14.32 & 1.95 & 14.28 & 1.79 & 0.890 \\
\hline
\end{tabular}

Statistical power was calculated based on the group of subjects with exclusive unilateral mastication where, hypothetically, a greater difference between both sides was expected. Besides, this group represents the weakest statistical condition, because it has a fewer amount of patients. Alveolar dimensions of $1 \mathrm{~mm}$ were considered as of clinical relevance. The power of statistical significance was found to be 0.78 , which corresponds to a $78 \%$ chance of having a real effect.

\section{Discussion}

The ideal masticatory pattern presents a similar number of masticatory cycles on both sides of the arches². However, most people show preference for one chewing side during the masticatory function ${ }^{7-9}$, which may be due to an adaptive process to problems such as tooth loss, occlusal interferences, morphology of the craniofacial bones and muscular and temporomandibular joint problems 9 . In the present study, the occlusal and dental characteristics that might interfere asymmetrically in the alveolar bone structure were controlled, and from the total of 39 participants, $72 \%$ had unilateral mastication (54\% preferred and $18 \%$ exclusive) and $28 \%$ had bilateral mastication. This distribution reflects what can be found in the general population where $73 \%$ to $77 \%$ have a preferred chewing side ${ }^{22}$. 
Besides being an adaptive process to the occlusal pattern, the choice for a preferred chewing side may be associated with the type of food and its texture ${ }^{3}$. In this study, the type of food was standardized for all analyses. Each participant received a portion of French bread sufficient to perform the filming of approximately 90 seconds. French bread was used in other research concerning the masticatory system with good acceptance from the population studied ${ }^{19}$. The filming technique and subsequent speech therapy evaluation are recommended strategies for the analysis of the masticatory pattern ${ }^{8,20,22}$. The video and the evaluations made by 3 speech therapists permitted a careful analysis by means of repeated visualizations and discussion of each case.

Cone beam computed tomography was used to evaluate the buccolingual dimension of the alveolar bone because it provides images without superimposition of structures with resolution and reliability sufficient to analyze the amount of bone and allow tridimensional manipulation of the structures under study ${ }^{23}$.

Research have evidenced the relationship between the preference for a chewing side and facial anthropometric measurements, demonstrating that unilateral masticatory function results in asymmetric changes of the maxilla and mandible ${ }^{24}$. Studies with rats have correlated masticatory hypofunction with reduction of the alveolar bone ${ }^{11,12,17}$. In the present study, however, subjects with preferred or exclusive unilateral mastication pattern did not show statistically significant differences in the buccolingual dimension of the alveolar bone between the preferred and non-preferred sides in the interdental regions evaluated in the maxilla and mandible.

Statistically significant differences were found at the heights of $6 \mathrm{~mm}$ and $8 \mathrm{~mm}$ between the first and second premolars on the right and left sides of the maxilla in patients with bilateral chewing. Since from a total of 40 comparisons made for these subjects ( 5 heights $\times 4$ interdental regions in maxilla and mandible), only 2 showed such variation, this result seems to reflect an isolated difference in the sample and it does not allow to infer that the masticatory pattern was responsible for the alterations found.

\section{Conclusions}

There was no difference in the transverse dimension of the alveolar bone in the posterior regions of maxilla and mandible between preferred and non-preferred sides in subjects with preferred unilateral mastication and between right and left sides in subjects with bilateral mastication.

\section{References}

1. Felício CM, Couto GA, Ferreira CLP, Mestriner Junior W. Reliability of masticatory efficiency with beads and correlation with the muscle activity. Pro Fono. 2008 Oct-Dec;20(4):225-30.

2. Hiemae K, Heath MR, Gillian H, Kazazoglu E, Murray J, Sapper D, Hamblett K. Natural bites, food consistency and feeding behaviour in man. Arch Oral Biol. 1996 Feb;41(2):175-89.

3. Raphangkorakit J, Thothongkam NE, Supanont N. Chewing-side determination of three food textures. J Oral Rehabil. 2006 Jan;33(1):2-7. 
4. Kazazoglu E, Heath MR, Muller F. A simple test for determination of the preferred chewing side. J Oral Rehabil. 1994 Nov;21(6):723.

5. Wilding RJ, Lewin A. The determination of optimal human jaw movements based on their association with chewing performance. Arch Arch Oral Biol. 1994 Apr;39(4):333-43.

6. Farias Gomes SG, Custodio W, Moura Jufer JS, Del Bel Cury AA, Rodrigues Garcia RCM. Correlation of mastication and masticatory movements and effect of chewing side preference. Braz Dent J. 2010;21(4):351-5.

7. Diernberger S, Bernhardt O, Schwahn C, Kordass B. Self-reported chewing side preference and its associations with occlusal, temporomandibular and prosthodontic factors: results from the population-based Study of Health in Pomerania (SHIP-0). J Oral Rehabil. 2008 Aug;35(8):613-20. doi: 10.1111/j.1365-2842.2007.01790.x.

8. Martinez-Gomis J, Lujan-Climent M, Palau S, Bizar J, Salsench J, Peraire M. Relationship between chewing side preference and handedness and lateral asymmetry of peripher al factors. Arch Oral Biol. 2009 Feb;54(2):101-7. doi: 10.1016/j.archoralbio.2008.09.006

9. Christensen LV, Radue JT. Lateral preference in mastication: a feasibility study. J Oral Rehabil. 1985 Sep;12(5):421-7.

10. Nissan J, Gross MD, Shifman A, Tzadok L, Assif D. Chewing side preference as a type of hemispheric laterality. J Oral Rehabil. 2004 May;31(5):412-6.

11. Liu J, Jin Z, Li Q. Effect of occlusal hypofunction and its recovery on the three-dimensional architecture of mandibular alveolar bone in growing rats. J Surg Res. 2015 Jan;193(1):229-36. doi: 10.1016/j.jss.2014.07.015.

12. Mavropoulos A, Kiliaridis S, Bresin A, Ammann P. Effect of different masticatory functional and mechanical demands on the structural adaptation of the mandibular alveolar bone in young growing rats. Bone. 2004 Jul;35(1):191-7.

13. Bourrin S, Palle S, Pupier R, Vico L, Alexandre C. Effect of physical training on boné adaptation in three zones of the rat tíbia. J Bone Miner Res. 1995 Nov;10(11):1745-52.

14. Bresin A, Kiliaridis S, Strid KG. Effect of masticatory function on the internal bone structure in the mandible of the growing rat. Eur J Oral Sci. 1999 Feb;107(1):35-44.

15. Cardaropoli G, Araújo M, Lindhe J. Dynamics of bone tissue formation in tooth extraction sites. An experimental study in dogs. J Clin Periodontol. 2003 Sep;30(9):809-18.

16. Araujo MG, Lindhe J. Dimensional ridge alterations following tooth extraction. An experimental study in the dog. J Clin Periodontol. 2005 Feb;32(2):212-8.

17. Denes BJ, Mavropoulos A, Bresin A, Kiliaridis S. Influence of masticatory hypofunction on the alveolar bone and the molar periodontal ligament space in the rat maxilla. Eur J Oral Sci. 2013 Dec;121(6):532-7. doi: 10.1111/eos.12092.

18. Suhr ES, Warita H, lida J, Soma K. The effect of occlusal hypofunction and its recovery on the periodontal tissues of the rat molar: ED1 immunohistochemical study. Orthod Waves. 2002;61:165-72.

19. Hitos SF, Solé D, Periotto MC, Fernandes ML, Weckx LL, Guedes ZC. Standardization of the registration and analysis of mastication: proposal for clinical application. Int J Orofacial Myology. 2011 Nov;37:47-56

20. Barcelos DC, da Silva MA, Batista GR, Pleffken PR, Pucci CR, Borges AB, et al. Absence or weak correlation between chewing side preference and lateralities in primary, mixed and permanent dentition. Arch Oral Biol. 2012 Aug;57(8):1086-92. doi: 10.1016/j.archoralbio.2012.02.022.

21. Felício CM, Folha GA, Ferreira CL, Medeiros AP. Expanded protocol of orofacial myofunctional evaluation with scores: Validity and reliability. Int J Pediatr Otorhinolaryngol. 2010 Nov;74(11):1230-9. doi: 10.1016/j.jporl.2010.07.021. 
22. Macdonnell ST, Hector MP, Hannigan A. Chewing side preferences in children. J Oral Rehabil. 2004 Sep;31(9):855-60.

23. Garib DG, Calil LR, Leal CR, Janson G. Is there a consensus for CBCT use in Orthodontics? Dental Press J Orthod. 2014 Sep-Oct;19(5):136-49. doi: 10.1590/2176-9451.19.5.136-149.sar.

24. Nascimento GKBO, Lima LM, Freitas MCR, Silva EGF, Balata PMM, Cunha DA, et al. Preference side masticatory and facial symmetry in total laryngectomy: clinical and electromyographic study. Rev CEFAC. 2013 Nov-Dec;15(6):1525-32. doi: 10.1590/S1516-18462013000600015. 